TP Periodica Polytechnica

Mechanical Engineering

\author{
58(1), pp. 47-53, 2014 \\ DOI:10.3311/PPme.7422 \\ Creative Commons Attribution (i)
}

RESEARCH ARTICLE

\section{Water purification of arsenic- contaminated drinking water via air gap membrane distillation (AGMD)}

\author{
Ershad Ullah Khan, Andrew R. Martin
}

RECEIVED 28 August 2013; ACCEPTEd 14 January 2014

\begin{abstract}
Arsenic contamination in shallow tubewell water is a serious health issue in Bangladesh and other Southeast Asian countries. Rural and remote areas in these locations continue to face tremendous challenges in providing access to affordable and safe arsenic-free drinking water. In recent years, intensive efforts have been undertaken to identify appropriate technologies for arsenic removal. This study examines one approach by investigating the application of suitable membrane technologies, specifically air gap membrane distillation (AGMD), as a promising method for small-scale, low cost deployment. The objective of this study was to test an AGMD commercial prototype (nominal capacity of $2 \mathrm{~L} / \mathrm{hr}$ ) with three different feedstocks: arsenic-containing groundwater (medium concentration) and arsenic-spiked tap water (medium and high concentrations). Results show that the tested AGMD prototype is capable of achieving excellent separation efficiency, as all product water samples showed arsenic levels well below WHO accepted limits $(10 \mu \mathrm{g} / \mathrm{L})$ even for initial concentrations over $1800 \mu \mathrm{g} / \mathrm{L}$. Parametric studies with focus on variation of coolant temperature illustrate the possibility of integrating AGMD in various thermal systems.
\end{abstract}

\section{Keywords}

arsenic removal - air gap membrane distillation (AGMD) · internal heat recovery $\cdot M D$ performance

\section{Ershad Ullah Khan}

Department of Energy Technology, Royal Institute of Technology (KTH), Brinellvägen 68, 10044 Stockholm, Sweden

email: ershad.khan@energy.kth.se

Andrew R. Martin

Department of Energy Technology, Royal Institute of Technology (KTH), Brinellvägen 68, 10044 Stockholm, Sweden

\section{Introduction}

Bangladesh is a densely populated country with over $75 \%$ of the population living in rural areas. Like several developing Southeast Asian countries, Bangladeshi drinking water is contaminated with arsenic, and the country faces immeasurable health consequences as a result [1]. According to Tan et al. [2] $2010,20 \%$ of deaths in Bangladesh can be attributed to arsenic poisoning due to various diseases including lung, skin, and bladder and kidney cancers. Moreover, researchers estimate that around half of the nation's 154 million people have been seriously exposed to arsenic contaminated drinking water [2]. The groundwater of 50 districts out of a total of 64 districts contained arsenic higher than the country standard for shallow tubewell drinking water $(50 \mu \mathrm{g} / \mathrm{L})$, and in around 60 districts groundwater was contaminated with arsenic levels higher than WHO recommendations $(10 \mu \mathrm{g} / \mathrm{L})$ [3]. Uddin et al. [4] report that the range of arsenic concentration in groundwater of Bangladesh is between $0.25 \mu \mathrm{g} / \mathrm{L}$ to $1600 \mu \mathrm{g} / \mathrm{L}$.

A key challenge towards overcoming arsenic poisoning is the development and implementation of water treatment technologies that meet several tough demands: technically sound, robust in operation, cost effective, and environmentally compatible. Several technologies have been tried for removal of high arsenic concentration arsenic from tubewell drinking water; see Table 1 for a summary. The commonly used conventional methods employ adsorption processes - coagulation and ion exchange [4]. Incorporating such processes is viable economically only at a large scale in centralized water treatment plants, requiring heavy capital outlays and skilled staff in addition to the necessary distribution systems and their maintenance. Therefore alternatives are needed for distributed deployment and operation in small communities.

Reverse osmosis (RO), a widespread membrane technology for a broad range of capacities, exhibits very good to excellent separation efficiencies and has potential as a water treatment technology in this context. However drawbacks like formation of polarization film, fouling, and high electricity consumption are limiting factors [5]. Several experimental results showed 
that reverse osmosis (RO) is an effective method for separation of arsenic up to $90 \%$; however RO failed to remove arsenic concentration to safe levels when groundwater arsenic concentrations are very high [6]. Membrane distillation (MD) has also been considered as an alternative technology for arsenic removal. In short MD is a thermal water purification process involving a hydrophobic, microporous membrane. Hot feed is kept on one side of the membrane, and a vapor pressure difference is established across the membrane via cooling on the opposite side. Water evaporates from the feed, passes through the membrane, and condenses; all non-volatile components are retained in the liquid phase, thus ensuring extremely high separation efficiency and high product water purity. Khayet and Matsuura [7] provide a comprehensive overview of MD technology and applications. Pangarkar and Sane [8] mention MD's advantages over other technologies like low-grade energy utilization, low pressure and cost, and possibility to integrate MD with combined electricity, heat, cooling, and other energy services (i.e. polygeneration). A few MD studies have specifically considered arsenic removal. Qu et al. [9] experimentally investigated direct contact membrane distillation (DCMD) for arsenic removal; DCMD was found to have a higher removal efficiency rate (above 99.95\%) than RO and also exhibited the ability to treat high-concentration arsenic solutions. Manna et al. [1] and Pal and Manna [10] achieved almost 100\% As separation efficiency in a laboratory-scale DCMD unit supplied with heat from an evacuated tube solar collector. Small scale vacuum membrane distillation (VMD) was tested for arsenic contaminated water at low feed temperatures [11], and excellent separation efficiency was demonstrated.

Air gap membrane distillation (AGMD) has also been proposed as a promising approach that combines the excellent separation characteristics of DCMD and VMD with lower specific thermal energy consumption [12]. Islam [13] studied arsenic removal by AGMD using a small-scale commercial prototype module and reported successful treatment of arsenic-contaminated groundwater in Bangladesh. Moreover, highly arsenic concentrated $(240 \mu \mathrm{g} / \mathrm{L})$ surface water in Högsby municipality in Sweden was treated in the lab, and arsenic concentration in the product water was below detection limits, $0.5 \mu \mathrm{g} / \mathrm{L}$ [13]. Kullab and Martin [14] investigated AGMD for flue gas condensate treatment in biomass-fired boilers; here product water in pilot-scale trials exhibited As levels below detection limits $(1 \mu \mathrm{g} / \mathrm{L})$, despite high levels of heavy metals and other hazardous components in the feedstock.

The integration of membrane distillation with industrial or power plant waste heat or with solar thermal systems offers several advantages including lower thermal energy consumption, reduction of overall energy consumption, reduction of greenhouse gas emissions, reduced pure water production costs due to waste heat recovery, and effective process integration for multiple products. Temperature levels on the hot side (up to $90^{\circ} \mathrm{C}$ ) are amenable to thermal integration with a variety of appropriate sources. Moreover, the cold side temperatures can be increased to fairly high levels (up to $70^{\circ} \mathrm{C}$ ) while exhibiting reasonable yields, opening up further possibilities for thermal integration. Considering the socio-economic situation of rural areas in Bangladesh, AGMD seems difficult to be applied alone due to high capital cost and energy consumption; therefore an integrated approach could be a viable alternative. Recently Khan et al. [15] proposed a biogas integrated system with AGMD in Bangladesh for pure water and clean energy provision, and Kumar et al. [16] have presented a solar hot water system with integrated AGMD for water purification.

The above studies indicate that AGMD is a promising technology for producing arsenic-free drinking water, however further research is required to firmly quantify actual performance in terms of separation efficiency and thermal energy consumption for near-commercial modules. Such data is necessary for the design of integrated small-scale polygeneration systems featuring MD. The present investigation addresses this issue via an experimental investigation of a household AGMD water purifier prototype ( $2 \mathrm{~L} / \mathrm{hr}$ nominal capacity) supplied by HVR Water Purification AB, Stockholm (subsidiary of Scarab Development AB). A parametric variation of coolant-side inlet temperature was conducted for plain and As-spiked tap water along

Tab. 1. Comparison of water purification methods for arsenic removal

\begin{tabular}{cccc}
\hline Method & As separation efficiency & Cost & Comments \\
\hline Filtration & low & low & Uncertain/ incomplete As removal \\
Carbon absorption & medium & low & Uncertain/ incomplete As removal \\
RO & high & high & high electricity demand \\
DCMD & high & high & High thermal energy consumption \\
VMD & high & high & High thermal energy consumption and complex vacuum system \\
AGMD & high & high & High thermal energy consumption \\
MSF & high & high & Suitable only for large scale systems \\
Flocculation & Medium to high & medium & Suitable only for large scale and complex water distribution systems \\
\hline
\end{tabular}


with As-contaminated groundwater, and the resulting yield and thermal energy consumption were determined.

\section{Methodology}

\subsection{AGMD experimental setup}

Fig. 1 shows a schematic of the AGMD system. Two immersion heaters (combined rate of $4.5 \mathrm{~kW}$ ) provide temperature control to feedwater contained in a 24 liter tank. A small circulation pump and bypass valve allow the hot-side flow rate to be controlled, and a rotameter is employed to measure flowrate. Once-through tap water is used as a heat sink, which can be heat exchanged with an external source to raise the inlet coolant temperature to the desired level. Here a second rotameter with built in control valve measures cold water flowrate in the cooling channel. Product water is measured with a graduated cylinder and stopwatch, typically during a 30-minute period of steady operation. To measure the feed and cold temperatures, thermocouples were installed at the inlets and outlets of the module and were connected to a data logger (Keithley 2701 DMM with a 7706 card). Experimental errors are as follows: temperature, $+/-2.0^{\circ} \mathrm{C}$; flow rate, $+/-0.1 \mathrm{~L} / \mathrm{min}$; yield, $+/-0.02$ $\mathrm{L} / \mathrm{hr}$; and conductivity $\pm 1 \mu \mathrm{S} / \mathrm{cm}$. The AGMD module consists of a $2.4 \mathrm{~cm}$ separation between two vertical condensations plates, behind which are located serpentine cooling channels.
A polypropylene cassette with membranes attached to either side is placed between the condensation surfaces (cassette dimensions $42 \mathrm{~cm}$ wide by $24 \mathrm{~cm}$ high, total membrane area 0.19 $\mathrm{m}^{2}$ ). This arrangement provides for an initial gap of $9 \mathrm{~mm}$ on each side, although the actual gap size is reduced by bulging of the membranes during operation. The feedstock is introduced at the bottom of the cassette and flows out from the top, as seen in Fig. 1 (b). The membrane material is PTFE (polytetrafluoroethylene, supplied by Gore) with a porosity of $80 \%$ and thickness of $0.2 \mathrm{~mm}$.

\subsection{Experimental procedure}

The AGMD experiments consist of analyzing the performance of the system under different operating conditions, namely various cold-side temperature levels. The operating conditions on the cold side included a flow rate of $1.9 \mathrm{~L} / \mathrm{min}$ and a range of coolant inlet temperatures: $15^{\circ} \mathrm{C}, 30^{\circ} \mathrm{C}, 45^{\circ} \mathrm{C}$, $55^{\circ} \mathrm{C}$, and $70^{\circ} \mathrm{C}$. On the hot side, the temperature was kept constant at about $80^{\circ} \mathrm{C}$, with a constant feed flow of $3.8 \mathrm{~L} / \mathrm{min}$. Flowrates are selected to lie in the upper range in terms of ensuring low $\Delta T$ across the particular side while keeping pressure drop (linked to pumping power requirements) and absolute pressure (linked to membrane liquid entry pressure limitations) at reasonable levels.

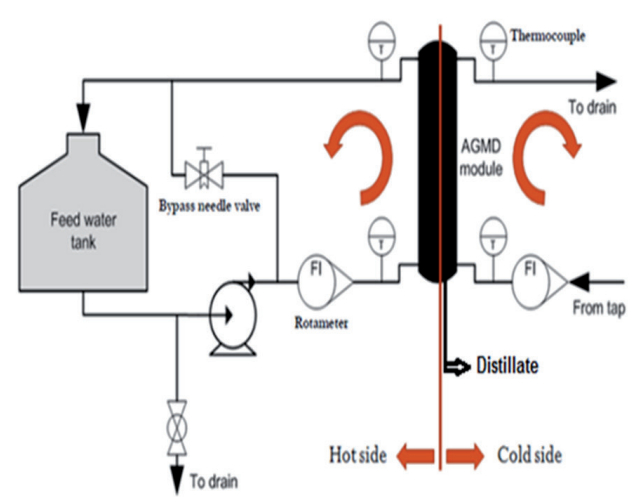

(a)

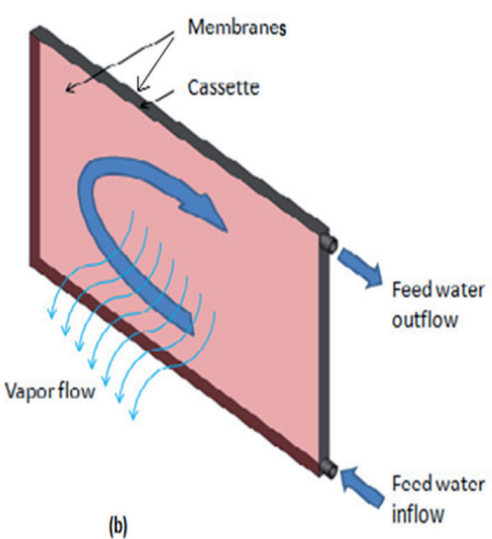

(b)

Fig. 1. (a) MD bench scale unit setup at KTH (b) Membrane Cassette (MD)

Tab. 2. Primarily chemical constituents of tested feedwaters

\begin{tabular}{ccccc}
\hline \multirow{2}{*}{ Parameter } & Unit & $\begin{array}{c}\text { As-contaminated groundwater } \\
\text { (Högsby municipality, Sweden) }\end{array}$ & $\begin{array}{c}\text { As-spiked tap water, high } \\
\text { concentration }\end{array}$ & $\begin{array}{c}\text { As-spiked tap water, } \\
\text { medium concentration }\end{array}$ \\
\hline $\mathrm{As}$ & $\mu \mathrm{g} / \mathrm{L}$ & 366 & 1800 & 300 \\
$\mathrm{Ca}^{2+}$ & $\mathrm{mg} / \mathrm{L}$ & 64 & 40 & 50 \\
$\mathrm{Mg}^{2+}$ & $\mathrm{mg} / \mathrm{L}$ & 21 & 10 & 12.5 \\
$\mathrm{Na}^{+}$ & $\mathrm{mg} / \mathrm{L}$ & 17.4 & 15 & 100 \\
$\mathrm{~K}^{+}$ & $\mathrm{mg} / \mathrm{L}$ & 6.44 & 5 & 5 \\
Conductivity & $\mu \mathrm{S} / \mathrm{cm}$ & 270 & 250 & 8.2 \\
$\mathrm{pH}$ & & 8.48 & & 250 \\
\hline
\end{tabular}


The initial conductivity of plain, contaminated groundwater and arsenic-spiked tap water is about $250 \mu \mathrm{S} / \mathrm{cm}$ at $25^{\circ} \mathrm{C}$. The arsenic contaminated groundwater was collected from Högsby municipality in Sweden and the sample water was analyzed by ICP-OES (measurement standard deviation is $< \pm 1 \%$ ). The arsenic spiked water was synthesized from $\mathrm{CaSO}_{4} \cdot 2 \mathrm{H}_{2} \mathrm{O}$, $\mathrm{MgSO}_{4}, \mathrm{Na}_{2} \mathrm{CO}_{3}$ and $\mathrm{KNO}_{3}$. Feedwater characteristics are shown in Table 2.

\section{Results}

\subsection{Parametric study}

The performance of the AGMD prototype is evaluated by analyzing pure water flow rates and specific thermal energy requirements $\left(\mathrm{kWh} / \mathrm{m}^{3}\right)$ as a function of feed and coolant temperature difference. As mentioned previously, experiments were performed for high and low temperature differences across the membrane for tap water and arsenic-spiked water. A feedstockto-coolant temperature difference $\Delta T$ is defined for reference purposes:

$$
\Delta T=T_{f i}-T_{c i}
$$

where $T_{f i}$ and $T_{c i}$ are the inlet temperatures of the feed and coolant, respectively. Fig. 2 shows the effect of this temperature difference on permeate flux at constant feed flow and coolant flow rate (the temperature difference is based on inlet conditions). The results show the increase of permeate flux with increase in temperature difference, an expected observation owing to the higher driving forces in this scenario. A small but significant flux is measured at a very low temperature difference, corresponding to a coolant temperature of around $70^{\circ} \mathrm{C}$, which has implications for heat recovery on the cold side (see next section). Permeate flux was not significantly influenced by the arsenic concentration in the feed solution. Overall the performance of the AGMD commercial prototype is within expectations, although the permeate flux has been reported to be much higher in DCMD and VMD (2-6 times increase, respectively) [7, 17].

Internal heat recovery can be achieved by AGMD since the modules allow the latent heat of vaporization to be transferred to the coolant channel via the distillate. The specific thermal energy consumption has been estimated in two ways:

Enthalpy drop across the hot side,

$$
Q_{1}=\dot{m}_{h} c_{p h}\left(T_{h i}-T_{h o}\right) / \dot{m}_{p}
$$

Net enthalpy change,

$$
Q_{2}=\left[\dot{m}_{h} c_{p h}\left(T_{h i}-T_{h o}\right)-\dot{m}_{c} c_{p c}\left(T_{c o}-T_{c i}\right)\right] / \dot{m}_{p}
$$

where $\dot{m}$ is the mass flow rate and $c_{p}$ is the specific heat for cold (subscript $c$ ), hot (subscript $h$ ), and product water streams (subscript $p$ ); subscripts $i$ and $o$ denote inlet and outlet, respectively. It was assumed that $c_{p}$ values $(4.2 \mathrm{~kJ} / \mathrm{kg} \mathrm{K})$ are same for

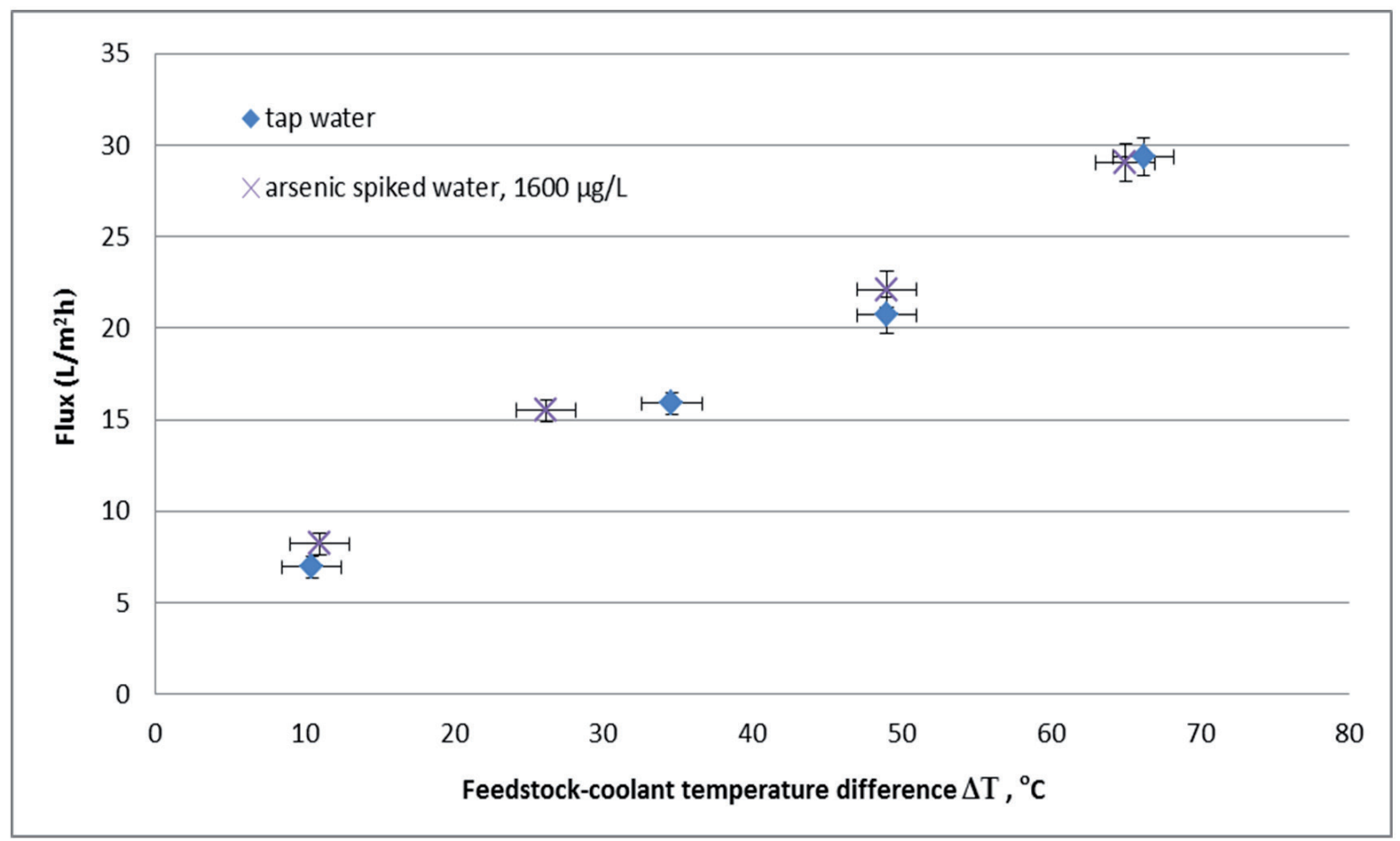

Fig. 2. Product water flux as a function of temperature difference across the membrane (feedwater flow $3.8 \mathrm{~L} / \mathrm{min}$, coolant flow $1.9 \mathrm{~L} / \mathrm{min}$, feedwater inlet temperature ca $80^{\circ} \mathrm{C}$, coolant inlet temperature varying) 
the contaminated feeds and cooling water. Feedwater flow rates ( $\left.\dot{m}_{h}\right)$, cooling water flow rates $\left(\dot{m}_{c}\right)$, feed inlet and outlet temperature and cooling inlet and outlet temperatures are shown in Table 3.

Fig. 3 shows this data as a function of feedstock-to-coolant temperature difference. Specific thermal energy consumption as defined by shows a weak correlation to temperature, especially when considering the high level of uncertainty in propagated errors. The slight increase at higher $\Delta T$ is attributed mainly to the fact that the enthalpy drop across the hot feedstock side rises at a faster rate than the concomitant augmentation in product water yield (Fig. 2). The opposite trend can be seen in the specific thermal energy consumption as defined by $Q_{2}$, i.e. as the feedstock-coolant temperature difference is raised, the rate of increase in product water yield dominates over the difference in net feedstock and coolant enthalpy change. Moreover heat recovery is enhanced with higher driving forces, which is reflected in a reduction of $Q_{2}$ at higher feedstock-coolant temperature differences.

\subsection{Product water quality analysis of contaminated groundwater and arsenic-spiked tap water feeds}

Values of product water conductivity were around 0.6 to 1.5 $\mu \mathrm{S} / \mathrm{cm}$ at $25^{\circ} \mathrm{C}$, indicating a very high purity level. The major advantage of AGMD process when compared with reverse osmosis or other purification technology is the relatively minimal effect of feed concentration on the flux and it was well observed in the present investigation. (With an increase of feed concentration in $\mathrm{RO}$, the performance of the system may significantly suffer as increased feed concentrations may reduce

Tab. 3. Inlet and outlet parameters

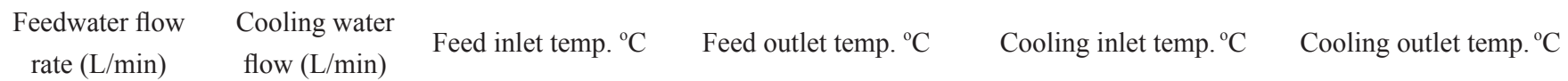

\begin{tabular}{lllccc}
\hline 3.8 & 1.9 & $80 \pm 2$ & $70 \pm 2$ & $15 \pm 2$ & $36 \pm 2$ \\
3.8 & 1.9 & $80 \pm 2$ & $72 \pm 2$ & $30 \pm 2$ & $47 \pm 2$ \\
3.8 & 1.9 & $80 \pm 2$ & $73.5 \pm 2$ & $45 \pm 2$ & $55 \pm 2$ \\
3.8 & 1.9 & $80 \pm 2$ & $76 \pm 2$ & $55 \pm 2$ & $65 \pm 2$ \\
3.8 & 1.9 & $80 \pm 2$ & $78 \pm 2$ & $70 \pm 2$ & $72.5 \pm 2$ \\
\hline
\end{tabular}

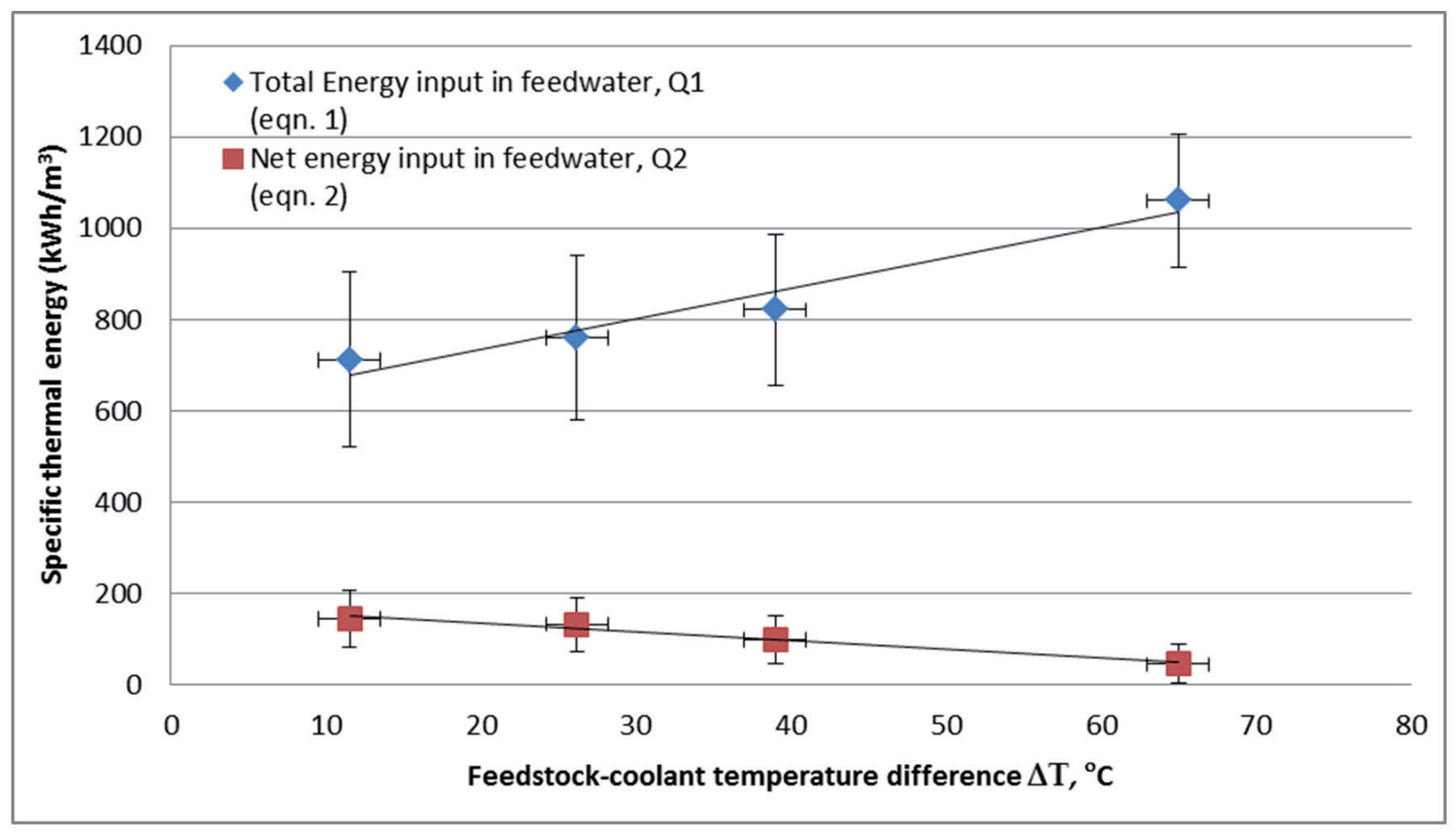

Fig. 3. Specific thermal energy consumption for AGMD module (feedwater flow $3.8 \mathrm{~L} / \mathrm{min}$, coolant flow $1.9 \mathrm{~L} / \mathrm{min}$, feedwater temperature ca $80^{\circ} \mathrm{C}$, coolant temperature varying) 
Tab. 4. Water quality analysis for distillate water (groundwater and arsenic-spiked tap waters)

\begin{tabular}{|c|c|c|c|c|}
\hline Parameter & Unit & $\begin{array}{l}\text { As-contaminated groundwater feed } \\
\text { (Högsby municipality, Sweden) }\end{array}$ & $\begin{array}{l}\text { As-spiked tap water feed } \\
\qquad(1800 \mu \mathrm{g} / \mathrm{L})\end{array}$ & $\begin{array}{l}\text { As-spiked tap water } \\
\text { feed }(300 \mu \mathrm{g} / \mathrm{L})\end{array}$ \\
\hline As & $\mu \mathrm{g} / \mathrm{L}$ & $<0.4$ & $<0.03$ & $<0.03$ \\
\hline $\mathrm{Ca}^{2+}$ & $\mathrm{mg} / \mathrm{L}$ & $<0.7$ & $<0.7$ & $<0.7$ \\
\hline $\mathrm{Mg}^{2+}$ & $\mathrm{mg} / \mathrm{L}$ & 0.014 & 0.002 & $<0.02$ \\
\hline $\mathrm{Na}^{+}$ & $\mathrm{mg} / \mathrm{L}$ & 0.02 & 0.012 & $<0.17$ \\
\hline $\mathrm{K}^{+}$ & $\mathrm{mg} / \mathrm{L}$ & $<0.03$ & $<0.03$ & $<0.03$ \\
\hline Conductivity & $\mu \mathrm{S} / \mathrm{cm}$ & $0.6-0.7$ & $0.6-1.5$ & $0.6-1.5$ \\
\hline $\mathrm{pH}$ & & 6 & 6 & 6 \\
\hline
\end{tabular}

the driving force for mass transfer across the membrane, thus increasing mineral passage through the membrane). Table 4 contains the product water analyses of the three different feeds (analyses conducted by Activation Laboratories Ltd, Ontario, Canada, and measurement standard deviation $\pm 0.5 \%$ ). The results are very promising in terms of arsenic concentration in the distillate, which was at extremely low levels. The analysis showed that the permeate arsenic concentration is not affected by operating parameters (like temperature and flow rate variations), and the concentration of arsenic in distilled remain below $0.4 \mu \mathrm{g} / \mathrm{L}$ for all the samples tested.

\section{Conclusions}

Air Gap Membrane Distillation has been demonstrated as a viable technology for arsenic removal with realistic feedstocks. Yields are maximized by increasing the temperature difference between feedstock and coolant, yet there is scope to utilize high coolant temperatures to achieve low specific thermal energy consumption and thus enhance heat recovery. Temperature levels on the hot side (at about $80^{\circ} \mathrm{C}$ ) are amenable to thermal integration with a variety of appropriate sources - biomass-derived waste heat, solar thermal, etc. Moreover cold side temperatures can be increased to fairly high amounts (up to $70^{\circ} \mathrm{C}$ ) while exhibiting reasonable yields, opening up further possibilities for thermal integration. Considering the socio-economic situation of rural areas in Bangladesh, AGMD seems difficult to be applied alone due to high capital cost and energy consumption. Therefore, an integrated system could be one of feasible and viable alternative to solve the safe and arsenic free drinking water. The future aim is to develop and commercialize a simple low-cost polygeneration system with an integrated biogas digester, gas engine, and AGMD unit, and activities are already underway.

\section{Acknowledgements}

The authors are appreciative to Prof. Gunnar Jacks, Department of Land and Water Resources Engineering, KTH, for helping the preparation of arsenic-spiked sample water. The authors are also extremely grateful to Chemistry lab at KTH for support for arsenic contaminated groundwater analysis.

\section{References}

1 Manna A. K., Sen M., Martin A. R., Pal P., Removal of arsenic from contaminated groundwater by solar-driven membrane distillation. Environmental Pollution, 158 (3), 805-811 (2010). DOI: $10.1016 /$ j.envpol.2009.10.002

2 Tan S. N., Yong J. W., Ng Y. F., Arsenic exposure from drinking water and mortality in Bangladesh. The Lancet, 376 (9753), 1641-1642 (2010).

DOI: $10.1016 / \mathrm{S} 0140-6736(10) 62090-9$

3 Chakraborti D., Rahman M. M., Das B., Murrill M., Dey S., Mukherjee S. C., Dhar R. K., Biswas B. K., Chowdhury U. K., Roy S., Sorif S., Selim M., Rahman M., Quamruzzaman Q., Status of groundwater arsenic contamination in Bangladesh: A 14year study report. Water Research, 44 (19), 5789-5802 (2010). DOI: $\underline{10.1016 / \text { j.watres.2010.06.051 }}$
4 Uddin M. T., Mozumder M. S. I., Figoli A., Islam M. A., Drioli E., Arsenic removal by conventional and membrane technology: An overview. Indian Journal of Chemical Techology, 14, 441-450 (2007).

5 Pangarkar B. L., Sane M. G., Guddad M., Reverse osmosis and membrane distillation for desalination of groundwater: A Review. ISRN Materials Science, Article ID 523124 (2011). DOI: $\underline{10.5402 / 2011 / 523124}$

6 Figoli A., Criscuoli A., Hoinkis J., Review of Membrane Processes for Arsenic Removal from Drinking Water. in 'The Global Arsenic Problem: Challenges for Safe Water Production', CRC Press, 131-146, (2010).

7 Khayet M., Matsuura T., Membrane Distillation: Principles and Application. Elsevier B.V., Oxford, UK (2011). 
8 Pangarkar B. L., Sane M. G., Performance of Air Gap Membrane Distillation for Desalination of Ground Water and Seawater. World Academy of Science, Engineering and Technology, International Science Index 51, 5(3), 756 - 760 (2011).

9 Qu D., Wang J., Hou D., Luan Z., Fan B., Zhao C., Experimental study of arsenic removal by direct contact membrane distillation. Journal of Hazardous Materials, 163, 874-879 (2009).

10 Pal P., Manna A. K., Removal of arsenic from contaminated groundwater by solar-driven membrane distillation using three different commercial membranes. Water Research, 44 (19), 5750-5760 (2010). DOI: $10.1016 /$ j.watres.2010.05.031

11 Criscuoli A., Bafaro P., Drioli E., Vacuum membrane distillation for purifying waters containing arsenic. Desalination, 323, 17-21 (2013). DOI: $\underline{10.1016 / j . d e s a l .2012 .08 .004}$

12 Sääsk A., The coming of membrane distillation technology. The International Desalination \& Water Reuse Quarterly, 19 (2), 41-46 (2009).

http://www.desalination.biz/news/magazine_article.asp?id=5145\&title
13 Islam A. M., Membrane Distillation Process for Pure Water and Removal of Arsenic. MSc thesis, Chalmers University of Technology, Sweden (2005).

14 Kullab A., Martin A., Membrane distillation and applications for water purification in thermal cogeneration plants. Separation and Purification Technology, 76 (3), 231-237 (2011).

DOI: $10.1016 /$ j.seppur.2010.09.028

15 Khan E. U., Mainali B., Martin A. R., Silveira S., TechnoEconomic Analysis of Small Scale Biogas Based Polygeneration Systems in Bangladesh. accepted for publication in Sustainable Energy Technologies and Assessments (2014).

16 Kumar U., Kayal H., Martin R. A., Sustainable Co-production of Drinking Water and Domestic Hot Water using Membrane Distillation Integrated Solar Thermal System. UAE Swiss Research Forum, AbuDhabi, Dubai, November 2012.

17 Alklaibi A. M., Lior N., Comparative Study of Direct-Contact and Air-Gap Membrane Distillation Processes. Industrial \& Engineering Chemistry Research, 46 (2), 584-590 (2007).

DOI: $10.1021 / \mathrm{ie} 051094 \mathrm{u}$ 